\title{
Análise da vida útil a partir de ensaios de carbonatação em postes de concreto
}

\author{
L. A. Reginato ${ }^{1 *}$, A. Lorenzi ${ }^{1}$, L.S. Lorenzi ${ }^{1}$, L.F. Caetano ${ }^{1}$, L.C.P. Silva Filho ${ }^{1}$ \\ *Autor de Contacto: 1csreginato@gmail.com \\ ${ }^{1}$ Departamento de Engenharia Civil, Escola de Engenharia, Instituto de Desempenho da UFRGS, Universidade \\ Federal do Rio Grande do Sul, Porto Alegre, Brasil
}

\begin{abstract}
RESUMO
O concreto é um dos materiais mais utilizado em obras de infraestrutura, inclusive nas redes de transmissão de energia. Nestas estruturas, onde o concreto é aparente e sujeito a ação de intempéries, seu desempenho é fundamental para a garantia de uma adequada vida útil de projeto (VUP). Entende-se que o aumento da vida útil dos postes de concreto armado pode colaborar para a redução da manutenção da rede de distribuição de energia, reduzindo o investimento em substituições ou reparos em postes por parte das concessionárias. Sendo assim, o presente trabalho buscou prever a VUP de postes de concreto, frente o mecanismo da carbonatação. Para a previsão da vida útil foram avaliados tres diferentes composições de traços para os postes de concreto armado: um usualmente utilizado por uma empresa de pré-moldados, e outros dois com traços aprimorados (com estudo de empacotamento de agregados) e com adicão de cinza de casca de arroz. Por meio da análise dos resultados, foi possível aprimorar o traço atualmente utilizado pela empresa, reduzindo o consumo de cimento e aumentando a vida útil dos postes de concreto armado de 10 para 60 anos. À vista disso, foi possível aumentar a vida útil do elemento, mesmo com a redução do consumo de cimento.
\end{abstract}

Palabras clave: Postes de Concreto; VUP; Carbonatação.

Citar como: L. A. Reginato, A. Lorenzi, L.S. Lorenzi, L.C. Caetano, L.C.P. Silva Filho (2021), "Análise da vida útil a partir de ensaios de carbonatação em postes de concreto", CONPAT 2021, XVI, pp. xxx-xxx, DOI: http://dx.doi.org/xxxxxxxxxx

\section{RESUMEN}


El hormigón es uno de los materiales más utilizados en obras de infraestructura, incluidas las redes de transmisión de energía. En estas estructuras, donde el hormigón está expuesto y sujeto a la acción de la intemperie, su desempeño es fundamental para garantizar una adecuada vida útil del proyecto (VUP). Se entiende que el aumento de la vida útil de los postes de hormigón armado puede contribuir a reducir el mantenimiento de la red de distribución de energía, reduciendo la inversión en reemplazos o reparaciones de postes por parte de los concesionarios. Así, el presente trabajo buscó predecir el VUP de postes de hormigón, frente al mecanismo de carbonatación. Para predecir la vida útil se evaluaron tres composiciones diferentes de mezclas para los postes de hormigón armado: una utilizada habitualmente por una empresa de prefabricados, y otras dos con características mejoradas (con un estudio de empaque de agregados) y con la adición de ceniza de cascarilla de arroz. . Mediante el análisis de los resultados se logró mejorar la traza que actualmente utiliza la empresa, reduciendo el consumo de cemento y aumentando la vida útil de los postes de hormigón armado de 10 a 60 años. Ante esto, se logró incrementar la vida útil del elemento, incluso con la reducción del consumo de cemento.

Palabras clave: Asistencia técnica; Costos; Manifestaciones patológicas.

\begin{abstract}
Concrete is one of the materials most used in infrastructure works, including energy transmission networks. In these structures, where concrete is exposed and subject to the action of bad weather, its performance is essential to guarantee an adequate project useful life (VUP). It is understood that the increase in the useful life of reinforced concrete poles can contribute to reducing the maintenance of the energy distribution network, reducing the investment in pole replacements or repairs by concessionaires. Thus, the present work sought to predict the VUP of concrete posts, facing the mechanism of carbonation. To predict the useful life, three different compositions of mixes for the reinforced concrete posts were evaluated: one usually used by a precast company, and another two with improved features (with a study of aggregate packing) and with the addition of ash of rice husks. By analyzing the results, it was possible to improve the trace currently used by the company, reducing cement consumption and increasing the useful life of reinforced concrete posts from 10 to 60 years. In view of this, it was possible to increase the useful life of the element, even with the reduction in cement consumption.
\end{abstract}

Keywords: Technical Assistance; Costs; Pathological Manifestations.

\title{
1. INTRODUÇÃO
}

Historicamente, a principal preocupação dos projetistas de concreto tem sido sua resistência mecânica. Porém, nos últimos anos, em função dos crescentes problemas de degradação precoce nas estruturas de concreto, observa-se uma tendência mundial no sentido de privilegiar os aspectos de projetos voltados à durabilidade e à extensão de sua vida útil (CLIFTON, 1993).

Em paralelo há o aumento da demanda por energia elétrica nas últimas décadas, ligado ao crescimento das unidades consumidoras, tonaram a operação e o controle dos sistemas elétricos uma tarefa complexa. Esta incumbência cabe ao Sistema Elétrico de Potência - SEP, o qual se divide basicamente em três macro setores: geração, transmissão e distribuição (GARCIA; DUZZI JR, 2012; TOSTES, 2012). 
Muitos dos elementos que compõem a rede de distribuição de energia são executados em concreto armado, desta forma é de suma importância que esses elementos sejam projetados, não somente em relação aos requisitos mecânicos, mas também em conceitos de vida útil. Atualmente, as normas de projeto de estruturas de concreto armado especificam relações água/cimento limites e classe de resistências mínima do concreto, em função da agressividade do meio onde a estrutura será inserida.

Além destes requisitos, as normas especificam cobrimentos mínimos de concreto, a fim de que seja mantida a Vida Útil de Projeto (VUP), isto é, o período efetivo de tempo durante o qual uma estrutura, ou qualquer um de seus componentes, satisfaçam os requisitos de desempenho do projeto, sem ações imprevistas de manutenção ou reparo (ISO 13823, 2008).

A preocupação com a VUP se dá pelo aumento das manifestações patológicas nos primeiros anos de construção dos elementos de concreto armado, principalmente dos construídos em concreto aparente, como é o caso dos postes de concreto utilizados nas redes de distribuição de energia. A garantia de adequado funcionamento para este tipo de estrutura é fundamenta para evitar interrupções no serviço de distribuição de energia elétrica. Além disto, mantendo a VUP é possível reduzir os custos ao longo da sua vida útil, uma vez que a maior durabilidade retarda a necessidade de troca de postes, além de reduzir o custo de manutenção dos mesmos.

Conforme a definição da NBR 8451-1 (ABNT, 2020, p.12): “A durabilidade do poste de concreto é a sua capacidade de resistir à ação das intemperes, ataques químicos, abrasão ou qualquer outro processo de deterioração; isto é, o poste de concreto deve conservar sua forma original, qualidade e capacidade de utilização quando exposto ao meio ambiente pelo período de vida útil estabelecido [...]". Cabe destacar que a durabilidade dos postes não é só referente aos processos de degradação inerentes, mas também pode ser afetada por outros mecanismos, como cargas de impacto, esofços de vento, entre outros.

A avaliação de durabilidade, relativa ao mecanismo de corrosão por carbonatação, dos postes de concreto armado é fundamental para analisar questões a cerca da vida útil e previsão dos seus ciclos de inspeção e manutenção. Desta forma, este trabalho buscou avaliar a dificuldade ou facilidade de entrada de água e gás carbônico no interior de três misturas distintas. A primeira é baseada em um traço usual utilizado por uma empresa de fabricação de elementos pré-moldados, as outras duas misturas se tratam do aprimoramento do traço, utilizando para isso o empacotamento dos agregados, e a adição de cinza de casca de arroz.

\section{REFERENCIAL TEÓRICO}

O sistema de distribuição de energia elétrica é um segmento do sistema elétrico de potência (SEP), o qual pode ser dividido basicamente em três macros setores: geração, transmissão e distribuição (GARCIA; DUZZI JR, 2012; TOSTES, 2012). Estes sistemas devem ter em vista certos padrões de confiabilidade, disponibilidade, qualidade, segurança e custos (LEÃO, 2009).

Com a constante otimização tecnológica do concreto armado, a produção de postes de concreto para linhas de transmissão e distribuição de energia elétrica vem crescendo substancialmente, principalmente no que diz respeito à substituição dos postes de madeiras por postes de concreto. Todavia, um dos principais pontos para que seja garantida a viabilidade da substituição dos postes de madeira por postes de concreto é garantia do prolongamento da vida útil destes elementos e, consequentemente, a manutenção dos mesmos. Neste sentido, alguns pontos devem ser melhor analisados durante o projeto e produção, com o intuito de assegurar e prolongar a vida útil.

Os postes de concreto armado são definidos como elementos pré-fabricados de concreto, classificados em função do formato, do comprimento e da resistência (ABNT, NBR 8451-1, 2020). Deste modo, os postes de concreto armado são elementos estruturais empregados em linhas aéreas 
de transmissão ou de distribuição de energia elétrica, além disso, podem ser utilizados também como suporte para a iluminação de vias públicas.

Segundo Giacon Júnior (2009), acreditava-se, inicialmente, que os postes de concreto armado não precisavam de manutenção, que teriam uma durabilidade ilimitada. Porém, essas características não são encontradas em nenhum material construtivo, pois todos desgastam-se e perdem resistência ao longo do tempo. Além disso, a durabilidade dos postes de concreto armado é dependente dos materiais, das características, das propriedades, dos cuidados envolvidos na produção dos mesmos e das condições ambientais.

Tendo em vista a importância dos postes de concreto armado no sistema de distribuição de energia, faz-se necessário que estes assegurem o fornecimento adequado de eletricidade à sociedade e atendam a exigência quanto à vida útil, evitando problemas no fornecimento de energia, bem como danos materiais e humanos em virtude de um eventual colapso desses elementos.

Deste modo, as oportunidades para o aperfeiçoamento dos postes de concreto armado, visando à durabilidade, podem ser identificadas no decorrer do ciclo produtivo, identificando-se os passíveis pontos e necessidades de aperfeiçoamento.

\subsection{Vida útil de estruturas de concreto armado}

A vida útil de uma estrutura representa o período efetivo de tempo, durante o qual uma estrutura, ou qualquer um de seus componentes, satisfaçam os requisitos de desempenho do projeto, sem ações imprevistas de manutenção ou reparo (ISO 13823, 2008).

Frente à estimativa da vida útil, a evolução nos estudos de durabilidade das estruturas de concreto armado possibilitou estimar esse parâmetro, principalmente devido ao avanço no conhecimento sobre os mecanismos de transporte de líquidos e de gases agressivos. Desta forma, foi possível associar o tempo aos modelos matemáticos que expressam quantitativamente esses mecanismos. Como resultado, a avaliação da vida útil passou a ser expressa em números de anos, e não apenas em critérios qualitativos de adequação da estrutura a um determinado grau de exposição (HELENE, 2004; MEDEIROS et al. 2011).

Através da utilização de métodos para estimativa da vida útil de estruturas de concreto armado, pode-se fazer uso de projetos de estruturas visando à durabilidade e à vida útil, realizando-se com um nível aceitável de confiabilidade, sendo admissível o uso de uma abordagem subjetiva. As recomendações normativas fornecem apenas definições qualitativas de exposição, não definindo a vida de projeto em relação à durabilidade. Em particular, as recomendações normativas não conseguem definir e quantificar os estados limites de durabilidade que devem ser ultrapassados para que a vida útil de projeto seja determinada (ROSTAM, 2005).

A vida útil, em suma, trata-se do tempo necessário para que atinja um nível mínimo aceitável de desempenho que comprometa a sua funcionalidade, caso ocorram medidas preventivas pode-se prolongar a vida útil da estrutura. Portanto o tempo de vida útil dependerá do critério a ser estabelecido para determinar o grau de desempenho inaceitável, ou o nível de deterioração máximo aceitável para uma estrutura de concreto armado. Para isso é necessário o conhecimento do mecanismo de degradação que irá atingir o limite mínimo de desempenho. O mesmo autor cita que dentre estes possíveis limites, pode-se citar o grau de fissuração do concreto, a perda de aderência entre a armadura e o concreto e a queda da capacidade estrutural, em virtude da perda de seção da armadura devido à corrosão da mesma.

Assim faz-se necessário, para que se obtenha a VUP, a compreensão e estudo dos modelos previsão e de degradação das estruturas de concreto. Para explicar o conceito de vida útil, Tutti (1982) propôs um modelo simplificado sob o ponto de vista da corrosão das armaduras dividido em dois períodos: o período de iniciação da corrosão e o período de propagação, conforme apresentado na Figura 1 (RIBEIRO, 2018). 


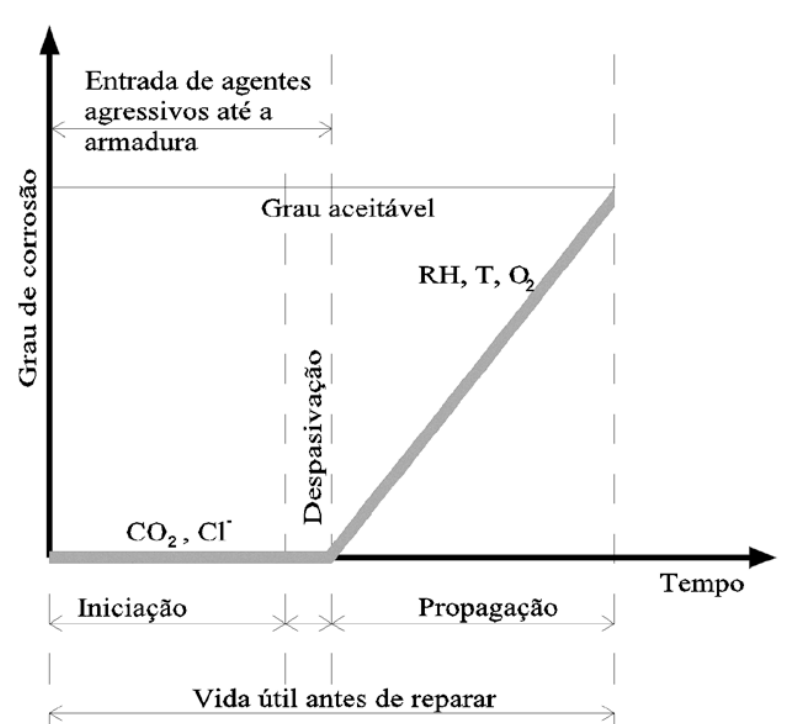

Figura 1. Modelo de Tuutti adaptado para corrosão de armaduras. (Fonte: Meira, 2017)

Consequentemente a vida útil de uma estrutura de concreto armado, tendo em vista o mecanismo da corrosão, engloba as três fases apresentadas no modelo de Tuutti adaptado (Figura 15) e pode ser pode ser representada de forma simplificada a partir do referido modelo. Conforme Meira (2017), nesse modelo simplificado a fase de iniciação é controlada principalmente pela porosidade do concreto, pela concentração e velocidade de transporte de $\mathrm{CO}_{2}$ e dos íons cloretos.

Quando os agentes despassivadores atingem a superfície da armadura, inicia-se o processo de despassivação da armadura, podendo assim dar início ao processo de corrosão, assim muitos autores e pesquisadores consideram que se atingiu a vida útil de projeto (VPU), uma vez que as características do concreto e a espessura do cobrimento devem ser especificadas e projetadas de forma que impeçam a despassivação da armadura (MEIRA, 2017; HELENE, 1993; MEDEIROS et. al, 2011).

\subsection{Alternativas de aperfeiçoamento de traços para postes de concreto armado}

A NBR 8451-1 (ABTN, 2020) estabelece alguns requisitos mínimos para a produção de postes de concreto armado destinados a linhas de transmissão e distribuição de energia elétrica. Estes requisitos variam principalmente de acordo com a classe de agressividade ambiental em que o elemento estará exposto.

Assim, cabe ao profissional habilitado a interpretação destes requisitos e a elaboração de materiais que sejam capazes de atingi-los. Ao mesmo tempo, o produto final deve possuir qualidade e ser competitivo economicamente. A partir destes pontos, surgem algumas lacunas para possíveis aperfeiçoamentos na produção de postes de concreto armado, com vista a atingir os requisitos mínimos exigíveis pelas regulamentações normativas e tornar o produto mais viável economicamente, mas sem prejuízos na qualidade do mesmo.

Dentro destas lacunas pode-se destacar: (1) dosagem do concreto, com a escolha adequada dos materiais componentes e suas combinações levando em consideração os requisitos exigíveis do material, bem como o método adequado para a proporção destes materiais; (2) aprimoramento da composição dos traços de concreto; (3) adição de materiais cimentícios suplementares; (4) adição de fibras na composição do concreto.

Uma estratégia para o aperfeiçoamento de traços de concreto é a diminuição do volume da pasta de cimento, que por sua vez contribui para a redução do custo final do mesmo. Sendo assim, para 
diminuir o volume da pasta de cimento o espaço entre os agregados deve ser substancialmente reduzido. Deste modo, o volume de pasta pode ser reduzido através da melhor proporção dos agregados, e um dos meios para se obter esta proporção é através do procedimento de empacotamento dos materiais constituintes da mistura (CHANG, 2004).

Este procedimento também é definido por Tutikian e Dal Molin (2008), como composição do esqueleto granular, o qual visa determinar a melhor proporção entre dois materiais de ordem crescente de partículas. Além deste procedimento, a utilização de areia artificial (também conhecida como areia de britagem ou pó de pedra) aprimora, juntamente com o uso de aditivos redutores de água, os traços de concreto.

\section{DEFINIÇÃO DOS TRAÇOS ANALISADOS}

Inicialmente, para a realização deste estudo, buscou-se obter informações dos materiais e do traço utilizado por uma empresa de pré- moldados, que produz postes de concreto. Esta etapa teve por objetivo obter dados reais em relação à vida util de postes que estão sendo comercializados no estado do Rio Grande do Sul, Brasil. De posse das informações pertinentes à pesquisa, buscou-se aprimorar o traço utilizado pela empresa, a fim de garantir menor permeabilidade do concreto, visto ser esta uma das principais propriedades para a garantia e aumento da vida útil dos elementos estruturais.

O aprimoramento do traço foi baseado, inicialmente, em estudos de empacotamento dos agregados miúdos e graúdos, a fim de garantir menor porosidade, possibilitando reduzir, inclusive, o consumo de cimento. Foram avaliados dois tipos de agregado miúdo (areia natural quartsoza e pó de brita basáltica) e dois agregados graúdos basalticos (brita de $12.5 \mathrm{~mm}$ e brita $19 \mathrm{~mm}$ de diâmetro máximo), sendo estes utilizados pela empresa que forneceu dados dos traço padrão.

O estudo de empacotamento do agregado graúdo consistiu na determinação da massa unitária compactada para diferentes proporções de brita 0 e brita 1 . Tendo sido obtido maior massa unitária compactada para a proporção de $65 \%$ de brita 1 e $35 \%$ de brira 0 , demonstrando este ser a relação de melhor empacotamento entre os agregados graúdos.

Já, para o empacotamento do agregado miúdo, o procedimento foi distinto, visto a maior possibilidade de perda das partículas finas. Sendo assim, o procedimento adotado foi a moldagem de argamassas com diferentes proporções de pó de brita e areia média. As argamassas foram moldadas na proporção de 1:3, com relação a/c de 0,55. Este estudo foi realizado para misturas só com cimento e com cimento e casca de arroz. Tanto para a argamassa de cimento, quanto para a argamassa de cimento e cinza de casca de arroz verificou-se que a proporção ideal entre os agregados miúdos foi de $50 \%$ de areia média e $50 \%$ de pó de brita. A metodologia e os procedimentos aplicados no estudo do empacotametnos dos agregados pode ser consultada em Reginato (2014).

Além dos estudos de empacotamento, foram realizados ajustes do teor de finos e incorporação de aditivos, de forma a garantir uma redução do consumo de cimento. Em relação ao traço padrão foi obtida uma redução do consumo de cimento, por $\mathrm{m}^{3}$ de concreto, de $429 \mathrm{~kg} / \mathrm{m}^{3}$ para $351 \mathrm{~kg} / \mathrm{m}^{3}$, ou seja, uma redução de $18 \%$ do teor de cimento. Essa redução na quantidade de cimento favorece uma redução do impacto ambiental, pois o cimento utilizado, por possuir $95 \%$ de clinquer na sua composição, apresenta alta emissão de $\mathrm{CO}_{2}$. Ao mesmo tempo, contribui para reduzir a possibilidade de fissuração em baixas idades, pois reduz a retração e a elevação térmica decorrente da hidratação do cimento. O traço obtido foi identificado como traço aprimorado (CAP).

O terceiro traço a ser analisado foi baseado no traço aprimorado, porém envolveu o estudo da substituição parcial do cimento por cinza de casca de arroz (CCA), um resíduo abundante na região 
sul do Brasil. Dessa maneira foi estudado um conjunto de traços denominados aprimorados com cinza de casca de arroz (CAP + CCA).

$\mathrm{O}$ que subsidiou este estudo foi reduzir o impacto ambiental, ao substituir uma parcela do cimento (que tem alta emissão de $\mathrm{CO}_{2}$ ) por um resíduo, que tem produção local e custo ambiental zero (sua utilização traz inclusive benefícios, pois resolve o problema de destinação final das cinzas depois da queima para recuperação do potencial calorífico).

Após os vários estudos realizados, verificou-se que o teor de substituição mais indicado, seria de $10 \%$ em massa do cimento, o que representa cerca de $15 \%$ em volume, a avaliação detalhada pode ser consultada em Reginato (2014). Diante disso, o traço com adição de CCA proporciona uma redução adicional do consumo de cimento de $31 \mathrm{~kg} / \mathrm{m}^{3}$ de concreto, quando comparado o traço aprimorado, sendo assim, possuindo um consumo de $314 \mathrm{~kg}$ de cimento por $\mathrm{m}^{3}$ de cimento. $\mathrm{Na}$ Tabela 1 é possível observar os traços utilizados para cada uma das três misturas.

Tabela 1- Traço utilizado para cada uma das misturas estudadas.

\begin{tabular}{|c|c|c|c|c|c|c|c|c|}
\hline Traço & Cimento & CCA & Areia & $\begin{array}{c}\text { Pó de } \\
\text { brita }\end{array}$ & $\begin{array}{c}\text { Brita } \\
\mathbf{0}\end{array}$ & $\begin{array}{c}\text { Brita } \\
\mathbf{1}\end{array}$ & $\begin{array}{c}\text { Relação } \\
\text { água/agl }\end{array}$ & Aditivo \\
\hline $\begin{array}{c}\text { Padrão } \\
\text { (original) }\end{array}$ & 1,0 & - & 2,09 & - & 1,62 & 0,51 & 0,59 & - \\
\hline $\begin{array}{c}\text { Aprimorado } \\
\text { (CAP) }\end{array}$ & 1,0 & - & 1,22 & 1,22 & 1,07 & 1,99 & 0,49 & $0,8 \%$ \\
\hline $\begin{array}{c}\text { Aprimorado }+ \\
\text { CCA (CAP + } \\
\text { CCA) }\end{array}$ & 1,0 & 0,1 & 1,05 & 1,05 & 1,38 & 2,56 & 0,49 & $0,8 \%$ \\
\hline
\end{tabular}

\section{PROGRAMA EXPERIMENTAL}

Após definido os traços de interesse foram moldados 09 (nove) postes em escala real, sendo três para cada uma das misturas apresentadas na Tabela 1. Os postes moldados foram tipo duplo T, com 9 metros de comprimento e carga nominal de 300 daN. Os requisitos dimensionais para este tipo de postes está descrito na NBR 8451-1 (ABNT, 2020), e apresenta os valores conforme Tabela 2.

Tabela 2 - Dimensões do poste utilizado e suas respectivas tolerâncias.

\begin{tabular}{|c|c|c|c|c|c|}
\hline $\begin{array}{c}\text { Identificação } \\
\text { Poste }\end{array}$ & $\begin{array}{c}\text { Comprimento } \\
\text { Nominal }\end{array}$ & \multicolumn{2}{|c|}{ Face A } & \multicolumn{2}{c|}{ Face B } \\
\cline { 3 - 6 } & Topo & Base & Topo & Base \\
\hline 03 B 300 daN & $9,00 \pm 0,05 \mathrm{~m}$ & $140 \pm 5 \mathrm{~mm}$ & $392 \pm 5 \mathrm{~mm}$ & $110 \pm 5 \mathrm{~mm}$ & $290 \pm \mathrm{mm}$ \\
\hline
\end{tabular}

As representações das faces A e B estão esquematizadas na Figura 2, tanto para o topo quanto para a base do poste.
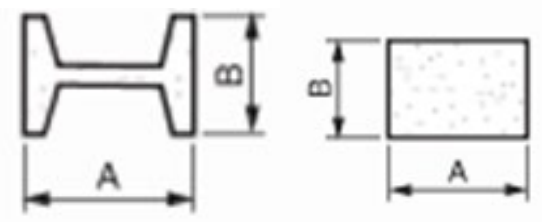
(a)

(b)

Figura 2. Representação das dimensões da seção transversal de base (a) e topo (b).

Os postes foram ensaiados quando ao comportamento mecânico de flexão aos 11 dias após sua moldagem, porém estes resultados não estão sendo apresentados neste trabalho. Posteriormente aos ensaios de flexão corpos de prova cilíndricos foram extraídos dos mesmos, conforme as orientações da NBR 7680 (ABNT, 2007), destaca-se que foi tomado o cuidado de executar as extrações das regiões sem presença de fissuras, originadas pela ruptura dos postes. No total foram extraídos 81 corpos de prova, sendo 27 deles com diâmetro de $30 \mathrm{~mm}$ e o restante com diâmetro de $95 \mathrm{~mm}$. Os corpos de prova de $95 \mathrm{~mm}$ de diâmetro foram utilizados para o ensaio de absorção de água e determinação da profundidade de carbonatação, enquanto que os de $30 \mathrm{~mm}$ foram utilizados para os ensaios de resistência à compressão.

De acordo com a Norma NBR 7680 (ABNT, 2007) recomenda-se o uso de corpos de prova, para ensaio de resistência à compressão, de $100 \mathrm{~mm}$ de diâmetro, ou com diâmetro 3 vezes maior do que a dimensão máxima do agregado. Entretanto, devido às limitações da espessura do poste, o qual apresenta alma de $50 \mathrm{~mm}$, a avaliação da resistência à compressão foi adotada em corpos de prova de $30 \mathrm{~mm}$ de diâmetro com o intuito de manter a relação da altura e diâmetro próximo a 2 . Além disto, comprovou-se estatisticamente a um nível de significância de $1 \%$ que há a possibilidade da utilização dos testemunhos menores que o recomendando pela NBR 7680 (ABNT, 2007), na avaliação de estruturas acabadas (Filho, 2007).

A determinação da resistência à compressão dos corpos de prova extraídos seguiu as recomendações da NBR 5739 (ABNT, 2007). A preparação das bases dos corpos de prova, foi realizada utilizando capeamento com argamassa de cimento, método recomendado pela NBR 5738 (ABNT, 2008), tomando-se os devidos cuidados para garantir o paralelismo entre as faces. Juntamente, foram determinadas as dimensões, a fim de determinar os coeficientes de correção para cada um dos corpos de prova submetidos ao ensaio, conforme recomendações da NBR 7680 (ABNT, 2007). Os ensaios foram realizados aos 28 dias após a moldagem dos postes.

Já para a determinação da absorção de água foi utilizado o método prescrito pela NBR 8451-4 (ABNT, 2011). O método consiste basicamente na imersão de corpos de prova, extraídos dos postes de concreto, em temperatura ambiente por um período não inferior a 24 horas. Decorrido este período foi determinada a massa saturada, até obter a constância de massa. Em seguida os corpos de prova são secos em estufa por um período de 24 horas

A medição das profundidades de carbonatação foi realizada em corpos de prova após 215 dias da moldagem dos postes. Os corpos de prova extraídos foram abertos para aspersão da fenolftaleína, sendo realizadas 3 medidas de profundidade de carbonatação para um mesmo corpo de prova. Esse procedimento foi executado para 3 exemplares de cada traço, proporcionando uma profundidade média confiável. Para o cálculo da vida util foi utilizado o modelo proposto por Tutti (1982) com a seguinte equação: $\mathrm{x}=\mathrm{k}$. $\sqrt{\mathrm{t}}$, que correlaciona o cobrimento $(\mathrm{x})$ e o coeficiente de carbonatação (k) com a raiz do tempo $(\mathrm{t})$. 


\section{RESULTADOS}

Os resultados da resistência à compressão dos corpos de provas extraídos estão apresentados na Tabela 3, juntamente com aplicação do coeficiente devido ao efeito de broqueamento, conforme Filho (2007). A tabela também apresenta, o desvio padrão obtido no ensaio para a determinação da resistência à compressão.

Tabela 3 - Resistência à compressão dos corpos de prova extraídos.

\begin{tabular}{|c|c|c|c|}
\hline $\begin{array}{c}\text { Identific } \\
\text { ação }\end{array}$ & $\begin{array}{c}\text { Resistência à Compressão CPs } \\
\text { Extraídos (MPa) }\end{array}$ & $\begin{array}{c}\text { Resistência à Compressão + Efeito de } \\
\text { broqueamento }(\mathrm{MPa})\end{array}$ & $\begin{array}{c}\text { Desvio Padrão } \\
(\mathrm{MPa})\end{array}$ \\
\hline Padrão & 41,0 & 45,2 & 4,8 \\
\hline CAP & 49,6 & 54,5 & 3,8 \\
\hline $\begin{array}{c}\text { CAP + } \\
\text { CCA }\end{array}$ & 50,8 & 55,9 & 7,7 \\
\hline
\end{tabular}

De acordo com os resultados apresentados é possível verificar que os corpos de prova extraídos dos postes, confeccionados com os traços aprimorado e aprimorado + CCA, apresentaram valores superiores ao concreto padrão utilizado pela empresa de pré moldado, sendo cerca de $21 \%$ e $24 \%$ superiores, respectivamente. Destaca-se que os traços aprimorados apresentaram maior resistência mecânicaapesar da redução significativo do consumo do cimento.

Em relação a determinação da absorção de água a NBR 8451-1 (ABNT, 2011) limita o valor do índice de absorção do concreto de acordo com as classes de agressividade ambiental, conforme Tabela 4.

Tabela 4 - Teores limites de absorção de água para postes de concreto armado.

\begin{tabular}{|l|l|l|}
\hline \multirow{2}{*}{$\begin{array}{l}\text { Classe de agressividade ambiental } \\
\text { (CCA) }{ }^{(1)}\end{array}$} & $\begin{array}{l}\text { Resultados dos corpos de prova que compõem a } \\
\text { amostra }{ }^{(2)}\end{array}$ \\
\cline { 2 - 3 } & Média (\%) & $\begin{array}{l}\text { Individual para cada corpo de prova } \\
(\%)\end{array}$ \\
\hline II & $\leq 5,5$ & $\leq 7,0$ \\
\hline III & $\leq 5,0$ & $\leq 6,5$ \\
\hline IV & $\leq 4,0$ & $\leq 5,5$ \\
\hline $\begin{array}{l}{ }^{(1)} \text { A classe de agressividade ambiental I NBR } 6118 \text { (ABNT, 2007) não se aplica a postes de } \\
\text { concreto; } \\
\text { (2) Para postes de concreto protendido, o índice de absorção deve ser reduzido em } 0,5 \% \text { sobre os } \\
\text { valores acima; }\end{array}$
\end{tabular}

Adaptado (NBR 8451-1, ABNT, 2011)

Os resultados obtidos nos ensaios de absorção de água são apresentados na Figura 3. 


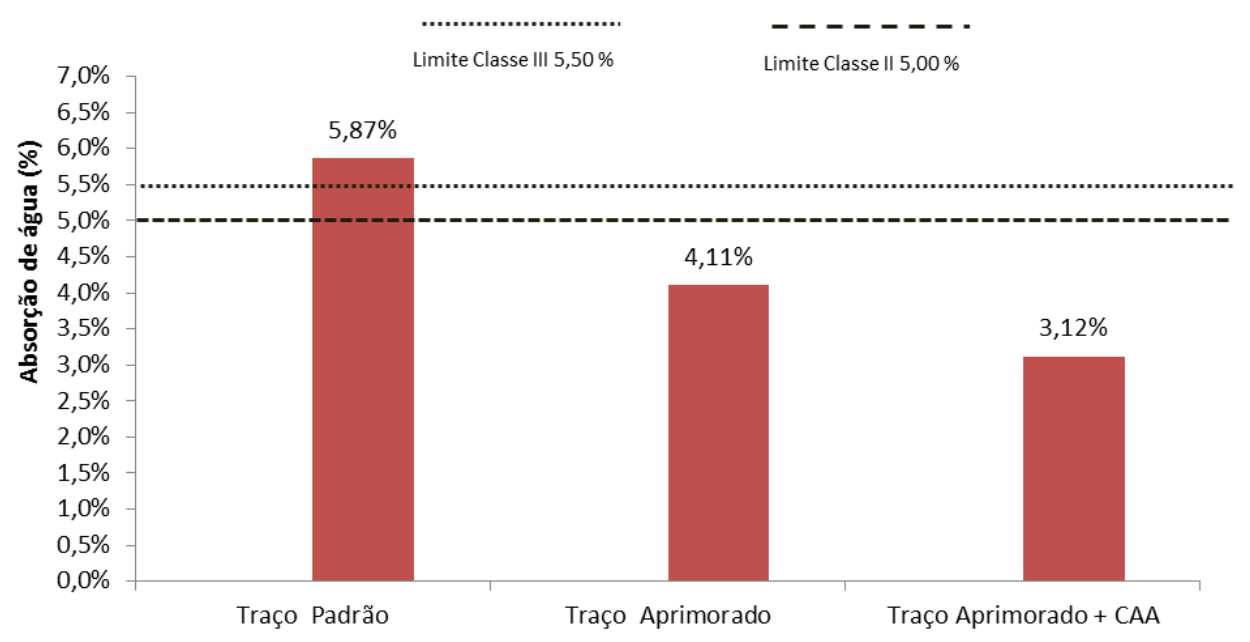

Figura 3. Absorção de água para cada traço moldado.

Analisando os resultados obtidos frente à absorção máxima de água exigida para as classes de agressividade II e III (ambiente urbano e marinha/industrial, respectivamente) pode-se constatar que os traços atualmente executados pela empresa (Padrão), apresentam maior absorção que a máxima permitida para ambas as classes de agressividade ambiental.

O traço Aprimorado apresentou absorção de água abaixo dos limites da classe de agressividade III e II, apresentando absorção de água de $4,11 \%$. Todavia, apenas os traços moldados com CCA atenderam as exigências de todas as classes ambientais, inclusive à classe de agressividade muito forte (classe IV), ficando abaixo de 4,00\% a absorção de água do concreto.

Em relação à durabilidade e vida útil, observando a Figura 4, os ganhos trazidos foram grandes. Ficou evidente que o traço atualmente utilizado (traço padrão) tem VUP estimada muito baixa, podendo despassivar a armadura em cerca de 10 anos (para cobrimento de $15 \mathrm{~mm}$ ). Isso tem um impacto enorme em relação à conservação de redes de energia. Com os traços aprimorados a VUP pode subir para cerca de 32 anos (CAP + CCA) ou 61 anos (CAP). Isso tem um efeito muito elevado nos custos ao longo do ciclo de vida dos postes e, isoladamente. O traço com $10 \%$ de cinza se mostrou especialmente promissor em termos de durabilidade para regiões com clima úmido ou marinho.

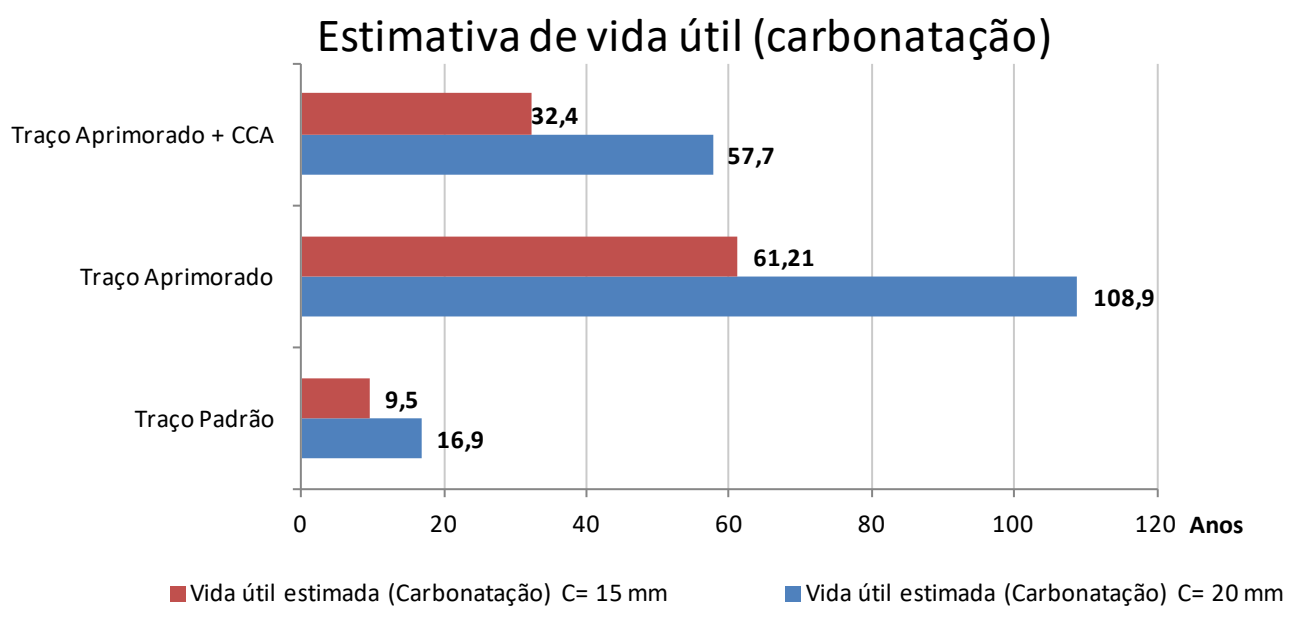

Figura 4. Estimativa de vida útil 


\section{CONCLUSÕES}

O estudo realizado resultou em avanços consideráveis em termos de redução de conteúdo de cimento, controle da fissuração, comportamento mecânico e durabilidade. Os resultados de durabilidade apresentaram um significativo incremento de desempenho quando comparado com os postes confeccionados com o traço padrão. Com aumento de cerca de $350 \%$ e $650 \%$ com cobrimento de $20 \mathrm{~mm}$ para os traços aprimorado + CCA e para o aprimorado, respectivamente.

Quanto à determinação da vida útil dos postes de concreto armado considerando corrosão por carbonatação, conclui-se que o poste moldado com o traço Aprimorado apresentou desempenho 6 vezes superior, quando comparado com o poste atualmente produzido pela empresa, elevando-se a vida útil de 10 para 60 anos com o cobrimento de $15 \mathrm{~mm}$. Juntamente conclui-se que o poste com adição de CCA possibilitou o aumento da vida útil para 33 anos.

O ganho significativo na durabilidade possibilita a execução de uma nova estratégia para o planejamento de manutenções e de reposição dos postes de concreto armado, reduzindo significativamento os custos com este tipo de operação.

\section{REFERENCIAS}

Associação Brasileira de Normas Técnicas. (2007). NBR 5739: Concreto - Ensaios de compressão de corpos de prova cilíndricos.

. (2008). NBR 5738: Concreto - Procedimento para moldagem e cura de corpos de prova.

. (2007). NBR 7680: Concreto - Extração, preparo e ensaio de testemunhos de concreto.

. (2020). NBR 8451-1: Postes de concreto armado e protendido para redes de distribuição e transmição de energia elétrica - Parte 1: Requisitos.

Chang, P.-K. An approach to optimizing mix design for properties of high-performance concrete. Cement and Concrete Research, v. 34, n. 4, p. 623-629, abr. 2004.

Clifton, J. R. (1993), Predicting the Service Life of Concrete. ACI Materials Journal, v. 90, n. 6, p. 611-617.

Garcia, D. A. A.; Duzzi JR, F. E. Capítulo II - Tópicos de sistemas de transmissão e de distribuição de energia elétrica. Revista O Setor Elétrico, São Paulo, ed. 74, p. 52, 2012. Disponível em < http://www.osetoreletrico.com.br/web/a-revista/edicoes >. Acesso em: 5 mar. 2020.

Giacon Junior, M. (2009), "Propagação de ondas de ultra-som em protótipos de postes tubulares de concreto armado", Dissertação (Mestrado em em Engenharia Agrícola) - Universidade Estadual de Campinas, Campinas, p.117.

Filho, O. V. (2007), “Avaliação da resistência à compressão do concreto através de testemunhos extraídos: contribuição à estimativa do coeficiente de correção devido aos efeitos do broqueamento", Trabalho de conclusão de curso, Universidade de São Paulo, São Paulo, p. 110. International Organization for Standartdization (ISO). (2008). ISO 13823: General principles on the design of structures for durability. 
Helene, P. A nova NBR 6118 e a vida útil das estruturas de concreto. In: Seminário de Patologia das Construções , 2, 2004, Porto Alegre. Anais... Porto Alegre: Novos Materiais e Tecnologias Emergentes, LEME, UFRGS, 2004

Helene, P. R. L. Contribuição ao Estudo da Corrosão em Armaduras de Concreto Armado. 1993. 223 p. Tese (Doutorado em Engenharia Civil) - Universidade de São Paulo, São Paulo, 1993.

INTERNATIONAL ORGANIZATION FOR STANDARTDIZATION (ISO). General principles on the design of structures for durability. ISO 13823. 2008

Leão, R. (2009), “GTD - Geração , Transmissão e Distribuição de Energia Elétrica”, Apostila de Aula, Universidade Federal do Ceará. Fortaleza. 38p.

Medeiros, M. H. F. De; Andrade, J. J. De O.; Helene, P. R. L. Durabilidade e vida útil das estruturas de concreto. In: ISAIA, Geraldo Cechella. Concreto: Ciência e Tecnologia. São Paulo / SP IBRACON, 2011 1v. cap 22 p. 773-807.

Meira, G. R. Corrosão de armaduras em estruturas de concreto armado: ensaios eletroquímicos. IFPB, 130 p. 2017.

Reginato, L. A. Otimização de traços de concreto: estudo aplicado a postes de concreto armado visando o aumento da vida útil. 2014. Dissertação (Mestrado em Engenharia) - Programa de PósGraduação em Engenharia Civil, UFRGS, Porto Alegre.

Ribeiro, D. V. Corrosão E Degradação Em Estruturas De Concreto. Elsevier, 2018. 416 p.

Rostam, S. Service life design of concrete structures -. v. 6, n. 5, p. 423-445, 2005.

Tostes, M. E. de L. (2012), “Distribuição de energia elétrica”, Apostila de Aula, Universidade Federal do Pará, Belém.

Tutikian, B. F.; Dal Molin, D. C. Concreto Auto-adensável. PINI. 144p. 2008.

Tutti, K. (1982), Corrosion of steel in concrete. Cement and Concrete Research, v. 504, p. 469. 